\title{
La coordinación institucional del ordenamiento territorial en México ${ }^{1}$
}

\author{
Vicente Ugalde ${ }^{2}$
}

\begin{abstract}
RESUMEN
Mediante el examen de la evolución de las entidades gubernamentales asociadas al ordenamiento territorial en México y de algunas de sus acciones durante el siglo $\mathrm{XX}$, este trabajo se interroga sobre si esas transformaciones han significado un cambio de fondo en las prácticas gubernamentales del ordenamiento territorial, o bien, si se ha tratado de modificaciones que en poco han contribuido a mejorar la eficacia de la intervención pública en ese rubro. El trabajo emprende una revisión de registros oficiales del gobierno federal para rastrear los cambios en esas instituciones, pero asimismo para identificar las prácticas gubernamentales que han incidido de forma más directa en la disposición de personas y actividades sobre el territorio. El resultado de ese ejercicio permite esbozar un cierto estado de las cosas del ordenamiento territorial actual en México.
\end{abstract}

Palabras clave: Ordenamiento del territorio, intervención pública territorial, marco jurídico del ordenamiento territorial, gestión del territorio.

\begin{abstract}
Through the analysis of the evolution of government entities associated with territorial organization in Mexico and some of their actions in the 20th century, this paper asks if these transformations have entailed a profound change in government practices regarding territorial arrangement or whether they have been modifications that have barely contributed to enhancing the effectiveness of public intervention in this area. It reviews the official records of the federal government in order to trace the changes in these institutions and to identify the government practices that have most directly affected the arrangement of people and activities throughout the territory. The result of this exercise provides a preliminary description of the current state of the territorial arrangement in Mexico.
\end{abstract}

Key words: Territorial arrangement, public intervention, legal framework for territorial arrangement, territorial management.

Cuando en México se habla de asentamientos humanos, de ordenamiento, o recientemente de ordenación del territorio, una cuestión se antepone de manera recurrente, y es que mientras se proclama que es prioritario organizar la distribución de actividades y personas en el territorio, no deja de señalarse las debilidades de la acción pública en la materia; algo así como si el país estuviera

\footnotetext{
1 Artículo recibido el 15 de diciembre de 2009 y aceptado el 19 de mayo de 2010.
}

condenado a un problema que siendo urgente, pareciera irresoluble. Si bien es cierto que existe una percepción más o menos generalizada según la cual la distribución de personas y actividades en el territorio nacional es irracional e incluso caótica, no podría negarse que, sin tratarse de una transformación de

\footnotetext{
2 Centro de Estudios Demográficos, Urbanos y Ambientales, El Colegio de México (México). E-mail: vugalde@colmex.mx. El autor agradece la colaboración de Giovanna Montagner.
} 
fondo, la acción del gobierno ha conocido una evolución en las instituciones jurídicas y gubernamentales asociadas al ordenamiento territorial.

Esa aparente estructuración coherente y racional que enmarca una parte importante de la intervención estatal en materia de ordenamiento territorial no está, sin embargo, al abrigo de superposiciones, inconsistencias y lagunas con respecto a las numerosas actividades de los diferentes sectores y niveles de gobierno que inciden en el ordenamiento territorial. Esta situación no debe extrañar pues deriva justamente de una sucesión de arreglos institucionales y legislativos que buscando inyectar algunas veces coherencia y otras equilibrio, no terminan por resolver la cuestión de qué entidad es la mejor dotada, la más apta, para ocuparse del ordenamiento del territorio.

La relación entre ordenamiento del territorio y su marco jurídico, plantea al menos dos cuestiones: por un lado, determinar si el objeto de la regulación, es decir, el ordenamiento del territorio, es efectivamente un ámbito concreto de intervención pública; por el otro lado, saber si ese objeto de intervención pública y entonces de regulación jurídica está asociado a un derecho y a instituciones jurídico-administrativas específicas.

Partiendo de las dificultades que atraviesa el ordenamiento de las actividades sobre el territorio y de la heterogeneidad de concepciones del ordenamiento territorial mismo, este artículo propone algunos elementos para responder a las preguntas planteadas. Dichos elementos habrán de aparecer a través de la revisión de una suerte de genealogía de la acción pública en materia de ordenamiento territorial. Es conveniente decir en este punto que las intervenciones públicas que inciden sobre el ordenamiento territorial comprenden tanto aquellas que se refieren al uso del suelo como aquellas que, buscando promover el desarrollo de las regiones, afectan de forma considerable la disposición de actividades y de asentamientos humanos en el territorio. Se trata, no tanto de revisar las competencias de los poderes públicos en sus tres órdenes de gobierno en materia de ordenamiento territorial, tema del que se ha ocupado con profundidad la literatura, especialmente a propósito de estudios sobre la descentralización y el desarrollo local ${ }^{3}$, sino de identificar algunas acciones de los poderes públicos que tienen impacto relevante en la distribución de actividades sobre el territorio en el régimen posrevolucionario. Luego, esta revisión se detendrá en la creación de una Secretaría de Estado que, por su vocación, tiene especial trascendencia en esta revisión y a partir de lo cual se presentan algunas apreciaciones desde el punto de vista jurídico e institucional sobre lo que fue o pudo ser una estrategia de convergencia, bajo un mando, de acciones de varios sectores y niveles de gobierno, con incidencia en la distribución de personas y actividades sobre el territorio. La idea es extraer de esta revisión esos elementos que, en una reflexión final, contribuyan a responder a los planteamientos relativos al estado actual de las condiciones jurídicas y administrativas del ordenamiento territorial en México.

\section{Del ordenamiento territorial como un objeto de intervención multisectorial...}

La cuestión a propósito de la condición del ordenamiento territorial o si se prefiere de la "política de ordenamiento territorial" como un ámbito de intervención pública, se refiere de cierta forma a la pertinencia y utilidad de ejercer una acción de los poderes públicos que incida en la localización de las actividades económicas en lugar de dejar que estas se dispongan en el territorio de manera espontánea. Visto así, el ordenamiento se presenta como propósito de la acción del Estado pero también como instrumento que persigue la mitigación de problemas y la prevención de males mediante la previsión razonada y razonable de la disposición de cosas y actividades; disposición que a su vez busca evitar males mayores respecto al empleo, al crecimiento económico, a la calidad de vida ${ }^{4}$.

\footnotetext{
3 A modo de ejemplo, los trabajos de Cabrero (1998), Cabrero (2005), Azuela (1999) y Aguilar et al. (1996), entre muchos otros, se han ocupado de la descentralización, el desarrollo local, las competencias de los municipios en materia de uso del suelo y el desarrollo regional, respectivamente.

4 Este propósito no le era extraño al Ejecutivo Federal que en 1976 emprendía una importante reforma a la administración para inscribir este campo de inter-
} 
Como lo señalan Monod \& De Castelbajac (1973), el ordenamiento del territorio busca contrarrestar un vicio consustancial al juego propio de la economía que consiste en una apreciación incompleta de los costos: el industrial que asume la decisión sobre dónde localizar su fabrica toma en cuenta los gastos directos de su inversión pero difícilmente considera los indirectos: agua, drenaje, vialidades, hospitales y escuelas.

El costo colectivo de esa decisión puede ser variado en función de muchos factores, pero es sin duda acumulativo y creciente si se considera la tendencia en la localización de ese tipo de actividades. El ordenamiento territorial se ve igualmente enfrentado al reto que significa el sentido de prospectiva que le debe caracterizar. Como lo apuntan estos autores (Monod \& De Castelbajac, 1973) a propósito de la ocupación del espacio, las principales decisiones de infraestructura -trazado de autopistas, establecimiento de prioridades en materia de orientación industrial, plan de desarrollo de las metrópolis- y la expansión de las áreas urbanas, implicarían una previsión de 20 a 30 años que no siempre está presente al momento de la toma de decisiones. En lugar de esto, el ordenamiento del territorio suele practicarse más bien en función del pasado y no del futuro: llevar servicios públicos, vialidades y empleo ahí donde los asentamientos humanos se han desarrollado.

Además, la intervención pública en el ordenamiento territorial debe enfrentar otro problema. Dominada por una visión que se plantea el problema de la redistribución geográfica de la riqueza y en general de bienes, debe enfrentarse cada vez más a un contexto de distribución ya no de los bienes y recursos sino de los males de la sociedad contemporánea. La pregunta evidente es entonces no únicamente si el ordenamiento territorial constituye un ámbito de intervención legítimo, sino

vención pública. "La política de asentamientos humanos estará encaminada a la distribución racional de los centros de población en el territorio nacional, de tal manera que se reduzcan los problemas que generan las grandes concentraciones humanas y se aprovechen las ventajas naturales de las diversas regiones con que cuenta el país". Iniciativa de Presupuesto de Egresos de la Federación para 1977. Diario de Debates del 15 de diciembre de 1976 también si esas funciones, que pueden ser conferidas al ordenamiento territorial, pueden constituir algo hacia lo que se puede dirigir una acción pública coherente y unificada; y asimismo, se trata de una pregunta sobre si los cambios recientes en el marco jurídico y en la arquitectura institucional habrán sabido adaptarse a estos desafíos.

El propósito de incidir en la disposición de actividades sobre el espacio encuentra desde el punto de vista del gobierno varias dificultades. Una de ellas, quizá la más importante desde esta perspectiva, consiste en que la administración está lejos de ser la organización monolítica que generalmente se percibe. Cada sector, cada secretaría y cada nivel de gobierno reivindican para sí una cierta autonomía para privilegiar la visión de las cosas que prevalece en el personal que los integra. Comunicaciones y Transportes piensa en sus puertos y carreteras, Educación Pública en sus escuelas, Comisión Nacional del Agua en sus ríos y cuencas, Secretaría de Economía en sus empresas, y así cada una de estas entidades reclama y ejerce sus formas muy propias y específicas de concebir y de hacer en sus respectivos ámbitos de acción. Determinada por la acción autónoma y orientada por la lógica particular de todas estas entidades, la pretensión de conformar una rectoría sobre distribución de actividades en el territorio, es decir, el ordenamiento territorial como objeto exclusivo de la lógica orientadora y de la acción de una entidad pública, está claramente comprometida.

El ordenamiento territorial ha sido, al menos desde mediados de la década de los setenta, presentado como un objeto de intervención adscrito o de la competencia de una rama específica de la administración pública federal: la Secretaría de Asentamientos Humanos y Obras Públicas primero (1976$1982)^{5}$, más tarde, Secretaría de Desarrollo Urbano y Ecología (1982-1992) y recientemente Secretaría de Desarrollo Social (1992 a

\footnotetext{
5 La intención de asociar un sector de intervención a un servicio administrativo específico, en este caso una Secretaría de Estado, quedó de manifiesto en la iniciativa de Ley Orgánica de la Administración Pública Federal y su exposición de motivos (Congreso de la Unión, 1976a).
} 
la fecha $)^{6}$. Por otro lado, al día de hoy el Ilamado sistema nacional de planeación democrática ${ }^{7}$ prevé un plan nacional de desarrollo del que se derivan programas sectoriales, institucionales, regionales y especiales. De los primeros se pueden derivar programas estatales y de estos a su vez programas municipales, como ocurre en materia de desarrollo urbano, pues así lo prevé la ley en materia de asentamientos humanos vigente desde 1976. A pesar de lo anterior, esa monosectorialidad y organización racional del quehacer de la Administración son tan solo aparentes, y que en diversos sectores como en el territorial han sido desarticuladas para hacer de ellos ámbitos de intervención de varias secretarías de Estado y de los tres órdenes de gobierno. En el caso del ordenamiento territorial se trató de un proceso en el que de lo disperso se transitó a la concentración en 1976 para luego volver a convertirse en una política susceptible de ejecutarse solo a través de la acción dispersa de muchas entidades públicas.

Una sucinta revisión de las etapas de la intervención pública en materia de ordenamiento del territorio o en otros ámbitos pero que inciden en este, permite identificar algunos de los momentos que han marcado esa transformación progresiva de la dispersión sectorial a la concentración y de esta nuevamente hacia a la dispersión. Si se prefiere, con esta revisión se esbozará una suerte de genealogía de la acción pública en esta materia. Se hará énfasis en la adscripción sectorial de las acciones en materia de ordenamiento del territorio con el objetivo de evidenciar la dispersión sectorial que marca hoy en día esta función estatal.

\footnotetext{
6 A junio de 2010 la Secretaría de Desarrollo Social está conformada en su estructura orgánica por tres subsecretarías, una de las cuales, la Subsecretaría de desarrollo urbano y ordenación del territorio, está a cargo, entre otras funciones, de las políticas de ordenación del territorio, de desarrollo urbano y regional, de suelo y reservas territoriales (Reglamento Interior de la Secretaría de Desarrollo Social, Diario Oficial de la Federación, 2006).

7 Este sistema fue introducido mediante una reforma a la Constitución (publicada en el diario oficial de la federación (Diario Oficial de la Federación, 3 de febrero de 1983). Como parte de ella se publicó la Ley de planeación (Diario Oficial de la Federación, 5 de enero de 1983 que abrogó la de 1930).
}

\section{La acción pública fragmentada}

La literatura se refiere, en general, a la década de los setenta como el momento clave de la intervención estatal en el ordenamiento territorial y como el origen del derecho urbanístico (Jiménez, 2006; Ward, 1991; Cortez y Delgadillo, 2008; Ruiz-Massieu, 1981). Ese momento es marcado por la aparición de la Ley general de asentamientos humanos (Congreso de la Unión, 1976b) ${ }^{8}$. Esta convención parece, sin embargo, omitir que tan solo en el México posrevolucionario y bajo el régimen jurídico de la Constitución de 1917, otras iniciativas ya se habían propuesto enmarcar, de forma tan sistemática y racional, el ordenamiento territorial ${ }^{9}$.

Al menos desde 1930, con la Ley sobre planeación general de la república (Diario Oficial de la Federación, 27 de enero de 1930 y Diario Oficial de la Federación, 12 de julio de 1930), los poderes públicos, bajo la conducción de la Secretaría de Comunicaciones y Obras Públicas, se habían propuesto "coordinar y encauzar las actividades de las distintas dependencias del gobierno para conseguir el desarrollo material y constructivo del país, a fin de realizarlo en una forma ordenada y armónica, de acuerdo con su topografía, su clima, su población, su historia y tradición, su vida funcional, social y económica, la defensa nacional, la salubridad pública y las necesidades presentes y futuras" (Diario Oficial de la Federación, 27 de enero de 1930). Desde esa época, un Plano Nacional de México preveía en base a sus características, funciones y usos o especializaciones potenciales, una clasificación del territorio nacional, no en regiones,

\footnotetext{
8 Esta ley fue precedida por una reforma a la Constitución por la que se introdujo el tema de los asentamientos humanos y estuvo acompañada por la aparición de la Ley de Desarrollo Urbano del Distrito Federal (Diario Oficial de la Federación, 7 de enero de 1976), el Plan general del plan director para el desarrollo urbano del Distrito Federal (Congreso de la Unión, 1976c) así como de instituciones ad hoc como la Comisión Nacional de Desarrollo Regional y Urbano (Diario Oficial de la Federación, 22 de junio de 1976) y como se verá más adelante, la Secretaría de Asentamientos Humanos y Obras Públicas.

9 Esta circunstancia fue anteriormente señalada por autores como Azuela (1989), Garza (2003) y Sánchez (1996).
} 
sino en zonas, así como una planeación y zonificación urbana y regional, y la formulación de planos reguladores para el distrito y territorios federales. Como lo han documentado varios estudios (Sánchez, 2005; Sánchez, 2002; Ronda y Ugalde, 2008), este primer aliento planificador, si bien imperfecto (Hiernaux y Torres, 2008), favoreció el ordenamiento territorial urbano, que se desarrolló con mayor alcance en el Distrito Federal ${ }^{10}$. No obstante, el elemento territorial fue perdiendo terreno frente al sectorial pues los sucesivos ejercicios de planeación del desarrollo, especialmente los llamados planes sexenales buscaron, sin omitir la variable territorial, marcar las directrices de las Secretarías de Estado en aras de favorecer el desarrollo de los diferentes ámbitos de intervención pública.

Junto a estas intervenciones o tentativas de intervención estatal presentadas como acciones en materia urbana o de planificación, otras, asociadas a sectores de intervención pública diferentes, tuvieron posiblemente impactos tanto o quizá más determinantes en el ordenamiento del territorio. Como bien lo apunta G. Garza (1992) las colonias agrícolas previstas por la Ley de la reforma agraria de 1915 fueron un mecanismo eficaz de colonización al menos en los primeros años del régimen posrevolucionario: tan solo entre 1923 y 1940, recuerda este autor, fueron establecidas 153 colonias agrícolas,

10 A modo de ejemplo: Ley de planificación y zonificación del Distrito Federal y Territorios de la Baja California (DOF 17-01-1933); Reglamento de la ley de planificación y zonificación (Diario Oficial de la Federación, 22 de febrero de 1933); Decreto que reforma el art. 5 de la Ley de Planificación y Zonificación del Distrito Federal y Territorios de Baja California (Diario Oficial de la Federación, 23 de noviembre de 1934); Ley de Planificación y Zonificación del Distrito Federal (Diario Oficial de la Federación, 31 de agosto de 1936); Reglamento de la ley de planificación y zonificación del Distrito Federal (Diario Oficial de la Federación, 31 de agosto de 1936); Decreto por el cual se demarcan las atribuciones que, en materia de planificación y zonificación, competen a la Comisión del ramo y a la Dirección General de Obras Públicas (Diario Oficial de la Federación, 14 de octubre de 1941); Decreto que modifica y deroga diversos artículos del reglamento de la ley de planificación y zonificación del Distrito Federal (Diario Oficial de la Federación, 28 de febrero de 1952). algunas de las cuales devinieron importantes ciudades ${ }^{11}$.

Este mecanismo de control sobre la disposición de asentamientos humanos sobre el territorio no va, desde luego, a desaparecer en los primeros años del periodo posrevolucionario: primero, durante los años cuarenta el Departamento Agrario tendrá la facultad de acordar la creación de nuevos centros de población agrícola, competencia que luego, a partir de los años cincuenta, se transforma en facultad para crear nuevos centros de población ejidal y que será responsabilidad del Departamento de Asuntos Agrarios y Colonización.

Iniciativas lanzadas desde un sector específico pero con impacto considerable en la disposición de actividades sobre el territorio se han sucedido a lo largo del siglo XX: así por ejemplo, las leyes de exención fiscal para industrias de la transformación ${ }^{12}$, o la Ley de industrias nuevas y necesarias, que, de acuerdo con Garza (2003), favoreció la concentración industrial en la región central $^{13}$. O bien, iniciativas relacionadas con la inversión pública en diversos puntos del territorio nacional para vías de comunicación desde la Secretaría de Hacienda y Crédito

11 Ver por ejemplo los numerosos contratos celebrados a partir de 1917 entre la Secretaría de Fomento y empresas colonizadoras o incluso personas físicas, al igual que los diferentes reglamentos emitidos por la Secretaría de Agricultura y Fomento para el servicio colonización de los diversos sistemas nacionales de riego. A manera de ejemplo el Reglamento para el servicio de colonización del Sistema nacional de riego $N^{\circ} 1$ Presidente Calles (Diario Oficial de la Federación, 7 de enero de 1933).

12 Durante los años cuarenta, es posible identificar en el Diario Oficial de la Nación alrededor de 230 autorizaciones para la exención de impuestos otorgadas a empresas y particulares por la Secretaría de Hacienda y Crédito Público. A manera de ejemplo, la autorización a favor de la empresa Hojalata y Lámina, S. A. (Diario Oficial de la Federación, 6 de abril de 1946); durante los años cincuenta y sesenta, son alrededor de 1.000 las autorizaciones de exención de impuestos a empresas específicas publicadas en el Diario Oficial de la Nación.

13 Ley que exime del impuesto sobre actividades mercantiles e industriales a las industrias nuevas en el Distrito Federal (Diario Oficial de la Federación, 15 de diciembre de 1942), de responsabilidad no de la SHCP, sino del Departamento del Distrito Federal. 
Público $(\mathrm{SHCP})^{14}$, más tarde desde la Secretaría de Comunicaciones y Obras Públicas ${ }^{15}$, o luego con la creación del Departamento de planeación y fomento de carreteras vecinales (Diario Oficial de la Federación, 24 de junio de 1947), órgano dependiente de la SHCP.

No únicamente en materia de infraestructura de comunicaciones, sino también a través de iniciativas de naturaleza más enfocada al desarrollo de una región específica, es como el ordenamiento del territorio fue objeto de intervenciones públicas. A modo de ejemplo, el Programa Nacional Fronterizo (1962), y con él, la Comisión mixta de desarrollo urbano fronterizo (con representación de diversas Secretarías de Estado, del Banco de México y de Ferrocarriles Nacionales); o aunque con una vocación no menos enfocada al desarrollo regional, la llamada política de parques y ciudades industriales $(G a r z a, 1992)^{16}$.

La acción pública con alta incidencia en la disposición de actividades en el territorio no solo fue lanzada bajo el aura del desarrollo asociado a la producción industrial y a la accesibilidad de mercancías a las ciudades o a los mercados transfronteras, otras veces estaba vinculada a regiones con características específicas. Así, la llamada Comisión Nacional de Zonas Áridas (Diario Oficial de la Federación, 5 de diciembre de 1970), dependiente de la Secretaría de Agricultura y Ganadería, fue concebida para la promoción del desarrollo en ese tipo de zonas a lo largo del país. Estos casos, entre otros varios de acción pública que fueron lanzados durante el periodo que va de 1940 a los años setenta ${ }^{17}$, sugieren que

14 Por ejemplo con el Decreto por el cual se autoriza al Ejecutivo para ministrar el gobierno del Estado de San Luis Potosí la cantidad de cincuenta mil pesos con destino a la construcción de carreteras (Diario Oficial de la Federación, 10 de febrero de 1927).

${ }^{15}$ Como lo fue la creación del Comité Pro carreteras del valle de Mexicali (Diario Oficial de la Federación, 11 de abril de 1947).

16 Aunque las iniciativas en esta materia datan de los años cincuenta, su consolidación está marcada por la constitución, por parte de la SHCP, de un fideicomiso para los "estudios y fomento de conjuntos, parques y ciudades industriales en las entidades federativas del país" (Diario Oficial de la Federación, 24 de diciembre de 1970).

17 Otras iniciativas relevantes para la disposición de actividades y personas sobre el territorio nacional la acción pública que es determinante en el ordenamiento del territorio no solo atañe a diferentes sectores de la Administración, sino que proviene, en una medida importante, del gobierno federal (Figura № 1 ).

Esta diversidad de polos emisores de acciones públicas no solo corresponde al tema del ordenamiento, como lo señala A. Azuela (1986) para el caso de la planificación urbana, o Bazant (2001) para el desarrollo urbano en las periferias, además de la intervención de los gobiernos municipales que es central en la gestión del uso del suelo urbano, la intervención del gobierno federal ha sido importante no solo cuando se trata de puertos, aeropuertos, ciudades petroleras o polos de desarrollo industrial y turístico, sino también a través de acciones en materia de vivienda, seguridad pública, educación, salud e infraestructura, y a través de la incorporación de tierra de núcleos agrarios, ejidales o comunales a la urbanización, sea en esas o en muchas otras ciudades.

\section{La coordinación intersectorial}

Ante la circunstancia de la acción pública dispersa, los gobiernos suelen reaccionar con dos tipos de respuesta: las instancias y esfuerzos de coordinación intersectorial por un lado; y por otro lado, la creación de una entidad encargada de conducir tanto la coordinación intersectorial como la intergubernamental.

Aunque es en la actualidad cuando esta expresión se ha puesto de moda en la jerga política y administrativa, tiempo atrás se había tomado conciencia de que la "transversalidad" era una cualidad necesaria para el éxito de la intervención pública en algunos ámbitos. En efecto, contrariamente a lo que sugiere hoy en día el uso extendido y banalizado del término "transversalidad", no es

son revisadas en Garza (2003). Se trata de acciones como las Comisiones de Cuencas Hidrológicas, la creación de Nacional Financiera, que el autor considera como políticas de impacto territorial aislado, o bien, otras acciones que el autor asocia a la estrategia económica nacional, como los Decretos de Descentralización Industrial, la creación de la Siderúrgica Lázaro Cárdenas-Las Truchas, la Ley General de Población de 1973, o en ese mismo año, el Programa Integral de Desarrollo Rural. 
Figura $\mathrm{N}^{0} 1$

Leyes e instituciones en materia de ordenamiento territorial y de ordenamiento urbano, así como en otras materias con incidencia en el ordenamiento territorial

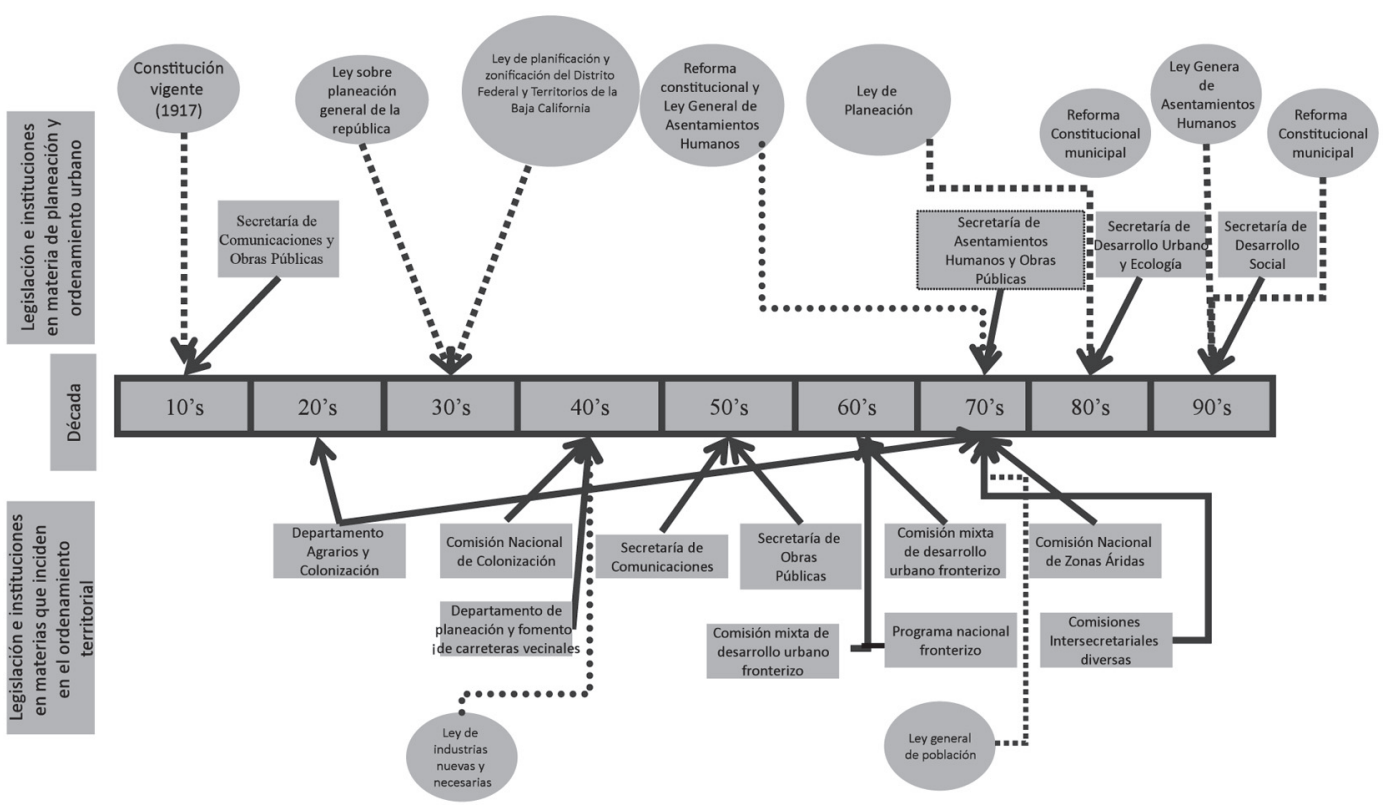

Fuente: Elaboración propia.

en los últimos años que se tomó conciencia de que algunos principios de la acción pública -como lo es el de aportar racionalidad a la disposición espacial de actividades económicas y de establecimientos de poblaciones- funcionan mejor como principios orientadores de acciones realizadas por diversos sectores de la administración. Obligados por esa condición, la búsqueda de soluciones llevó al gobierno federal, desde hace varias décadas, a ensayar dispositivos de diálogo intersectorial, algunos de los cuales fueron de existencia efímera o a veces únicamente formal, sin llegar a constituirse en verdaderos ámbitos de coordinación.

Algunos de estos dispositivos institucionales de coordinación intersectorial con incidencia en la disposición de actividades y poblaciones sobre el territorio fueron, por ejemplo, el Comité intersecretarial de la Habitación para los trabajadores a iniciativa de la Secretaría del Trabajo y Previsión Social (Diario Oficial de la Federación, 19 de noviembre de 1941); la Comisión intersecretarial de la región indígena del valle del Yaqui (Diario Oficial de la Federación, 16 de noviembre de 1951) promovida por la Secretaría de Recursos Hidráulicos; la Comisión intersecretarial coordinadora del levantamiento de la carta geográfica de la república mexicana, piloteada por la Secretaría de la Defensa Nacional (Diario Oficial de la Federación, 2 de enero de 1956); la Comisión intersecretarial integradas por la Secretaría de la presidencia y la SHCP para la formulación de planes nacionales para el desarrollo económico y social del país (Diario Oficial de la Federación, 2 de marzo de 1962); la Comisión intersecretarial para el fomento económico de la franja fronteriza norte y las zonas y perímetros libres, encabezada por la Secretaría de industria y comercio (Diario Oficial de la Federación, 11 de mayo de 1972); así como la Comisión intersecretarial conducida por el Departamento de asuntos agrarios y colonización para elaborar y ejecutar los planes regionales para la constitución y aprobación de centros de población ejidal (Diario Oficial de la Federación, 7 de julio de 1971). Otros organismos concebidos con el propósito de coordinar 
la acción para el desarrollo y diseñados con vocación no solo intersecretarial sino también intergubernamental, fueron los Comités promotores del desarrollo socioeconómico de los Estados de la República, Coprodes, que coordinados por la Secretaría de la presidencia y los gobernadores de los estados, constituían espacios de coordinación de programas del gobierno federal correspondientes a diferentes sectores pero en donde además se formulaban los planes regionales de desarrollo económico (por ejemplo para el Estado de Durango (Diario Oficial de la Federación, 16 de noviembre de 1973) y San Luis Potosí (Diario Oficial de la Federación, 12 de julio de 1974)). Erigidos como organismos públicos con personalidad jurídica y patrimonio propios, se encargó además a estos organismos de asesorar y coadyuvar con los gobiernos municipales en la planificación a nivel local. Con el mismo propósito fue creada la Comisión nacional de desarrollo regional (Diario Oficial de la Federación, 28 de enero de 1975) y la Comisión nacional de desarrollo regional y urbano (Diario Oficial de la Federación, 28 de junio de 1976), instancia en la que, bajo la dirección del secretario de la Presidencia de la República, convergieron altos funcionarios de las entidades y de algunas empresas públicas del gobierno federal con el propósito de formular planes de desarrollo en las nueve regiones que entonces se consideraron (Garza, 2003). Ni reciente ni efímero, el ánimo de realizar arreglos institucionales para hacer posible la incorporación de ideas y principios comunes a acciones de varias secretarías, dio lugar a lo largo de décadas al establecimiento y formalización de dispositivos de coordinación intersecretarial, dispositivos de los que, todavía hoy, se presume son la mejor respuesta institucional al imperativo de la transversalidad.

\section{... a la conformación de un sector}

La inestabilidad en la nomenclatura de la administración pública federal en México sugiere que los recurrentes cambios en los nombres de las secretarías de Estado obedecen a la coyuntura política más que a propósitos de modernización y mejora administrativa. Mientras que en administraciones públicas caracterizadas por estructuras y nombres más duraderos, los cambios de nombre o la apari- ción de una nueva secretaría representa una verdadera revolución, en México la ausencia de estabilidad hace parecer la creación de una nueva secretaría, no tanto como el reflejo de la adopción por parte del gobierno de nuevos ámbitos de intervención o de su sensibilidad hacia la necesaria evolución de aparato público dictada por la búsqueda de eficiencia, sino, más bien, como un cambio menor o, al menos, un gesto relacionado con la contingencia política que significa el cambio sexenal.

Esta apreciación no podría aplicarse a todos los casos que ha habido en México, sin incurrir en una valoración injusta y simplificadora. Para el caso del ordenamiento del territorio, la aparición de la Secretaría de Asentamientos Humanos y Obras Públicas (Diario Oficial de la Federación, 29 de diciembre de 1976) pudiera representar, como veremos, una excepción a esta idea.

\section{La aparición de una secretaría}

La intervención gubernamental en el tema de la organización del territorio tiene desde luego antecedentes remotos. Sin ir más atrás, el gobierno de Porfirio Díaz creó una Secretaría de Comunicaciones y Obras Públicas (Decreto publicado en el Diario Oficial de la Nación del 13 de mayo de 1891), la cual fue retomada, en 1917, por la Ley de Secretarías de Estados (Diario Oficial de la Federación, 14 de abril de 1917). La Ley de Secretarías de Estado promulgada por el presidente López Mateos (Diario Oficial de la Federación, 24 de diciembre, 1958) separó esta secretaría para dar lugar a una Secretaría de Comunicaciones (SC) y otra de Obras Públicas (SOP). En 1976, con la llegada del equipo del presidente López Portillo se dieron algunos cambios encaminados a imprimir cierta racionalidad a la administración pública ${ }^{18}$. Uno

\footnotetext{
18 Entre las diversas iniciativas para racionalizar la administración pública puede mencionarse la elaboración intensiva de planes de urbanismo y de la expansión y predominancia de la noción de asentamientos humanos, en especial con la aparición de la SAHOP. Sobre esa apreciación del inicio de la administración de López Portillo, véase Pardo (1991) y la Minuta Proyecto de Ley Orgánica de la Administración Pública Federal (Congreso de la Unión, 1976a).
} 
de ellos consistió en modificar la estructura y denominación de la SOP para dar lugar a la Secretaría de Asentamientos Humanos y Obras Públicas (SAHOP), que estaría compuesta por tres subsecretarías: Obras Públicas, Bienes Inmuebles y Obras Urbanas y Asentamientos Humanos (Secretaría de Asentamientos Humanos y Obras Públicas, s/f).

Con la aparición de la Ley Orgánica de la Administración Pública Federal (LOAPF) se establecieron las bases que la estructura administrativa observa hasta ahora. Algunos de los efectos más significativos de este esfuerzo de racionalización fueron la incorporación de la variable territorial por la vía de la política de asentamientos humanos ${ }^{19}$, la reestructuración del gabinete en base a sectores y la conformación de nuevos organismos de coordinación intersectorial.

Con estos ajustes, la cuestión del ordenamiento del territorio enfrentaba una encrucijada: o bien era concebido como un ámbito de intervención de una entidad especializada; o bien, como un aspecto que debía incorporarse a las acciones de otras entidades públicas. Esta alternativa es superada rápidamente por el gobierno: es el territorio el que deviene objeto de una atención especial por parte de una secretaría de Estado específica y serán otros los aspectos que deberán ser incorporados en la planeación del territorio como era el caso del medio ambiente que devino un elemento a tomarse en cuenta en los programas de desarrollo urbano y en las autorizaciones de uso del suelo (Wilk, 1989). El carácter transversal del ordenamiento territorial no dejará, sin embargo, de expresarse en la estructura fijada por la LOAPF.

\footnotetext{
19 Aunque tanto la ley como la Secretaría en cuestión se presentan bajo la noción de "asentamientos humanos", se trata de instrumentos de la política de ordenamiento del territorio urbano. El uso de dicha expresión está presumiblemente asociado a la activa participación del gobierno mexicano en la Conferencia Habitat I sobre Asentamientos Humanos, organizada por las Naciones Unidas en Vancouver en 1976. Al respecto, Azuela (2008) observa incluso que la noción de "asentamiento humano" prevista por la ley en la materia no tenía ninguna traducción normativa, sugiriendo que únicamente se había radicado en el régimen jurídico del ordenamiento del suelo urbano para ponerse a tono con la expresión utilizada en el plano internacional.
}

Como se ha mencionado, la LOAPF buscaba imprimir una cierta racionalidad al aparato administrativo. Producto de esta ley, a la existente Secretaría de Obras Públicas, creada por la Ley de Secretarías y Departamentos de Estado en vigor desde el 1 de enero de 1959, se agregó la tarea del desarrollo urbano y se le erigió como el órgano encargado del proceso de urbanización y del ordenamiento del territorio ${ }^{20}$. La nueva secretaría se presentaba, asimismo, como encargada de "planear la adecuada distribución de la población, el ordenamiento del territorio y la promoción de las obras públicas que requieren los asentamientos humanos" (Secretaría de Asentamientos Humanos y Obras Públicas, s/f). La unificación de esas importantes funciones parece acertada pues qué mejor medio para incidir en la distribución de actividades y de poblaciones sobre el territorio que el pilotear las acciones que tienen que ver con las obras públicas $^{21}$, y las que tienen que ver con la autorización del uso y destino del suelo ${ }^{22}$. Encargada de la coordinación del ordenamiento territorial, la nueva SAHOP debía de estar en condiciones de ubicarse por encima de los desafíos de la necesaria coordinación intersectorial a que hemos venido haciendo referencia pero también a la coordinación intergubernamental.

\section{Una centralización efímera y parcial}

Los efectos de la inscripción del tema de los asentamientos humanos en la Constitución en 1976 no fueron anodinos en el plano intergubernamental. El artículo 73 reformado atribuía al Congreso de la Unión la competencia para legislar en esa materia ${ }^{23}$

20 Este esfuerzo por organizar a la administración pública en lo concerniente al ordenamiento territorial se asemeja a algo ocurrido en Francia con la reforma del 15 de febrero de 1963 (Monod \& De Castelbajac, 1973) relativa al mismo tema.

21 Incluso la provisión de agua potable pasó a formar parte de la esfera de competencias de la SAHOP en detrimento de la recién desaparecida Secretaría de Recursos Hidráuclicos (Aboites, 2009).

22 En el esquema establecido por la Ley de 1958, las competencias y funciones relativas a la infraestructura correspondían a la Secretaría de Obras Públicas (artículo 11) mientras que lo relativo al ordenamiento del suelo urbano no estaban, al menos de manera directa, en el ámbito de competencias federales.

23 "Artículo 73. El Congreso tiene facultad para: [...] 
y con ello introducía la idea de la distribución "concurrente" de competencias entre la Federación, los Estados y los municipios ${ }^{24}$. De acuerdo con A. Azuela (1995), más que imponer límites a la propiedad, el objetivo de la reforma era transformar el régimen de competencias con lo que la Federación se inmiscuía en un ámbito hasta entonces reservado a los otros órdenes de gobierno. De esta manera, la reforma que para algunos autores como Rodríguez (1999) constituyó paso en favor de los municipios, también puede ser calificada como centralizadora en tanto que hasta entonces eran los Estados y a veces los municipios los que sin contar con la atribución constitucional estaban al cargo del desarrollo urbano.

En varios países de Europa, en el marco de la reconstrucción de sus economías luego de la Segunda Guerra Mundial, el Estado central desempeñó un papel importante en la política de ordenamiento del territorio. En algunos casos, esa conducción estuvo a cargo de entidades encargadas de fomentar el desarrollo industrial, como el Instituto Nacional de la Industria y su Plan de Estabilización en España (Carreras y Tafunell, 2004; Tortella, 1994), el Instituto para la Reconstrucción Industria en Italia (Tortella, 1995) y la DATAR en Francia (Monod \& De Castelbajac, 1973). En este último caso, el gobierno crea en 1945 una Misión de descentralización industrial; luego en 1950, se elabora un Plan nacional de ordenamiento del territorio y finalmente, el 14 de febrero de 1963, se crea la Delegación de ordenamiento del territorio y de

XXIX-C. Para expedir las leyes que establezcan la concurrencia del Gobierno Federal, de los Estados y de los Municipios, en el ámbito de sus respectivas competencias, en materia de asentamientos humanos, con objeto de cumplir con los fines previstos en el párrafo tercero del artículo 27 de esta Constitución". Los fines a los que se refiere el párrafo tercero del artículo 27 son: "Artículo 27. [...] en consecuencia, se dictarán las medidas necesarias para ordenar los asentamientos humanos y establecer adecuadas provisiones, usos, reservas y destinos de tierras, aguas y bosques, a efecto de ejecutar obras públicas y de planear y regular la fundación, conservación, mejoramiento y crecimiento de los centros de población [...]".

24 Se trata del Decreto de reforma de los artículos 27, 73 y 115 de la Constitución publicado en el Diario Oficial de la Federación del 6 de febrero de 1976. la acción regional (DATAR). En ese país, las grandes políticas de ordenamiento territorial fueron lanzadas por el Estado por medio de un Comité interministerial y del ordenamiento del territorio (CIAT) presidido por el Primer Ministro, así como a través de unos Fondos de intervención para el ordenamiento territorial (FIAT), creados al mismo tiempo que la DATAR y que fungieron como un incentivo económico considerable (Madiot, 1989). Esa centralización fue, sin embargo, progresivamente cediendo al otorgarse importantes competencias a las colectividades territoriales (gobiernos locales) y especialmente a las regiones en materia de ordenamiento territorial $^{25}$. En tanto que en México, al instaurarse un régimen de competencias "concurrente" en 1976, se centralizaba la rectoría del ordenamiento del territorio. Esta tendencia centralizadora no fue duradera y no tuvo tiempo de probar su eficacia pues fue revertida por una ola de descentralizaciones también originada en varios países de Europa.

Las reformas al artículo 115 en $1983^{26}$ y a la LGAH de $1984^{27}$ establecieron y ratificaron la facultad de los municipios para elaborar programas de desarrollo urbano y para la aplicación de los instrumentos de control de uso del suelo: permisos, autorizaciones, licencias, así como declaraciones de zonas de uso específico. Las reformas tenían entre otras consecuencias dar lugar a una cierta tensión en cuanto a la jerarquía de las leyes de los Estados en relación con la reforma misma y con la LGAH debido a que las leyes locales atribuían al Ejecutivo estatal la aplicación de muchos de esos instrumentos; y por otro lado, comenzaba a minarse la importancia de la Secretaría encargada del ordenamiento territorial, desde 1982, la Secretaría de Desarrollo Urbano y Ecología (SEDUE).

\footnotetext{
25 Balme et al. (1993) revisan cómo con la reforma de 1982 el Estado perdió importancia en materia de ordenamiento del territorio en beneficio de la región.

26 El Decreto de publicación de la reforma constitucional del 3 de febrero de 1983 ordenaba tanto a las legislaturas de los Estados como al Congreso de la Unión a, antes de un año de la entrada en vigor de ese decreto, reformar y adicionar las leyes federales así como las constituciones y leyes locales para proveer al cumplimiento de las disposiciones de la reforma (artículo $2^{\circ}$ transitorio)

27 Reforma publicada en el Diario Oficial de la Federación del 7 de febrero de 1984.
} 
Estos cambios impactan la cuestión a propósito de a qué orden de gobierno corresponde la aplicación de instrumentos jurídicos específicos, y con ello afectan la relación intergubernamental en materias que inciden en el territorio: desde que una actividad potencialmente tiene una localización territorial, son las autoridades del municipio (en virtud de los cambios legislativos mencionados y consolidados en la reforma al artículo 115 de 1999, Diario Oficial de la Federación, 23 de diciembre de 1999) quienes tienen la competencia correspondiente. Aunque las grandes obras de infraestructura (hospitales, penitenciarías, grandes conjuntos habitacionales, puertos, parques industriales) son formuladas y promovidas, en gran parte, por el gobierno federal, implican la participación de los gobiernos municipales en la medida en que estos son los que otorgan el permiso de construcción y la autorización de uso del suelo.

La reglamentación en materia de desarroIlo urbano puede, de esta forma, convertirse en elemento crucial de una iniciativa de este tipo, aun cuando en principio no haya sido concebida para ello. Esta última observación parece estar también en el centro de la cuestión sobre el ordenamiento del territorio en México. Se trata de saber si el ordenamiento territorial en tanto que acción de los poderes públicos que buscan incidir en la localización sobre el territorio de los bienes y recursos pero también sobre la mitigación de las crisis y problemas debe ser en última instancia una política conducida por el nivel federal o el municipal. Esta cuestión no es tan sencilla si se atiende a la circunstancia de que, en ambos niveles, pero sobre todo en el federal, no se trata, como se ha visto, de un único polo emisor de esas acciones, sino de entidades, desde el desmantelamiento de la SAHOP, de varios sectores.

\section{Consideraciones finales}

La mirada sobre las condiciones jurídicas y administrativas del ordenamiento territorial en México, sobre todo respecto a cómo la legislación y las instituciones administrativas han sido transformados, permite retomar la cuestión que abrió este artículo sobre si el ordenamiento del territorio ha constituido y debiera conformar un ámbito de intervención pública y de regulación jurídica asociado a un dere- cho y a una institución administrativa específica. Esta primera conclusión será sucedida por algunas consideraciones sobre una eventual política nacional de ordenamiento territorial.

\section{Ordenamiento territorial: un objeto de muchos derechos}

Las intervenciones gubernamentales, sea que están destinadas directamente a tener un impacto sobre el ordenamiento de las actividades económicas o de los asentamientos humanos sobre el territorio, sea que no tienen eso como objetivo primordial pero que indirectamente les impactan, son, como se ha podido apreciar, de naturaleza muy diversa y no provienen de una sola instancia gubernamental. Se trata pues, en el caso del ordenamiento territorial, de un ámbito de intervención pública que, a pesar de que en algún momento pareció que iba a concentrar en la SAHOP importantes competencias, hoy en día no cuenta con un referente institucional, es decir, con una secretaría o departamento específico, sino que es un objeto de intervención a partir de varias instancias y sectores de la Administración. La creación de la SAHOP constituye un momento excepcional en el diseño institucional del ordenamiento territorial que trataba de corregir la dispersión de iniciativas y acciones dado que concentraba competencias tanto para decidir la localización de importantes obras de infraestructura portadoras de una gran capacidad para orientar la localización de actividades económicas y de poblaciones sobre el territorio y al mismo tiempo la potestad de ejecutar dichas obras y de ordenar el territorio urbano. Sin embargo, producto del proceso de descentralización de 1983 y 1999 a favor de los municipios, las competencias en materia de planeación y gestión del desarrollo urbano se han delegado a este nivel de gobierno; y las competencias de diversas materias como lo es la política de infraestructura -caminos, puentes, puertos- o bien, en materia de fomento industrial y entre otras, de vivienda, ámbitos de intervención cuyas acciones tienen un enorme poder para incidir en la disposición de personas y actividades sobre el territorio, sigue siendo competencia del gobierno federal.

Se trata, en efecto, en el caso del ordenamiento del territorio, de un objeto que está en el cruce de muchos sectores y que en con- 
secuencia tiene un marco jurídico disperso en numerosas leyes, reglamentos, decretos, planes y programas. Esta dispersión nos hace pensar que estamos ante un objeto de regulación que es entonces "objeto de muchos derechos". En medio de esta multiplicidad de polos emisores de regulación jurídica del ordenamiento del territorio, podría, sin embargo, encontrarse que hay algunas intervenciones que inciden de forma más directa, es decir, que hay polos emisores de regulación sobre los asentamientos humanos que son más determinantes y cuya coordinación y coherencia son posibles. En este sentido, se puede acordar, quizá, que dos tipos de intervenciones estatales que influyen más directamente sobre el ordenamiento del territorio son esos que asociamos a las expresiones "asentamientos humanos" y "desarrollo urbano" por un lado; y por el otro, la "infraestructura" o bien las "obras públicas". El optimismo ante la factibilidad de una coordinación de estas dos grandes áreas de intervención naufraga rápidamente cuando vemos por ejemplo que a lo largo de las últimas cuatro décadas la organización de los poderes públicos para atender esas dos áreas ha oscilado entre dinámicas de concentración en un órgano y en un nivel de gobierno, y de dispersión de esas acciones gubernamentales. La expectativa de una mejor coordinación de esos dos tipos de intervenciones gubernamentales se disipa cuando vemos no solo que los esfuerzos de coordinación son raros, sino que, en la agenda pública del actual gobierno, el tema de la infraestructura ha prevalecido sobre otros aspectos del ordenamiento territorial: mientras que este tema motivó la rápida aparición de un programa ${ }^{28}$, el que debía sustituir al Programa nacional de desarrollo urbano y ordenación del territorio 2001-2006 no fue elaborado, o al menos publicado durante los primeros cuatro años de gobierno ${ }^{29}$. Por otro

28 El Programa Nacional de Infraestructura 2007-2012 fue dado a conocer en julio de 2007 apenas unos días después de la publicación del Plan Nacional de Desarrollo 2007-2012.

29 El Programa Nacional de Desarrollo Urbano y Ordenación del Territorio, correspondiente al gobierno de Vicente Fox (2000-2006), fue publicado en el Diario Oficial de la Nación del 27 de marzo de 2002. Hasta la fecha no se ha publicado el programa que lo sustituiría, siendo que el actual gobierno concluye en diciembre de 2012. lado, el papel de la Subsecretaría de Desarrollo Urbano y Ordenación del Territorio en el Programa nacional de infraestructura del gobierno federal (2007-2012) es, si no inexistente, marginal, mientras que los municipios si bien concebido como receptores pasivos de la gran cruzada por la infraestructura, permanecen a cargo de la planeación y gestión del territorio municipal, al menos, en el aspecto urbanístico.

Es justamente en este sentido que la SAHOP constituyó un esfuerzo portador de condiciones para trascender las dificultades planteadas por un objeto de intervención "no monosectorial". Se trataba de un avance hacia la institución de un sector de intervención a través de la conformación de una entidad pública rectora de esos dos campos de acción pública de gran impacto en el ordenamiento del territorio: los asentamientos humanos y las obras públicas. La evolución en las instituciones jurídicas y administrativas no sería en este sentido inexistente pero tampoco estaría marcada por una lógica lineal de mejora permanente en las prácticas gubernamentales de ordenamiento territorial. La posibilidad de una rectoría a las intervenciones en materia de infraestructura y de asentamientos humanos no será posible al parecer en el futuro inmediato.

\section{Reformas en materia de ordenamiento territorial en perspectiva}

Esta parte se limita a proponer un par de observaciones respecto a algunas medidas que pueden incidir en una eventual política nacional de ordenamiento territorial. No se trata, desde luego, de soluciones, sino de elementos que Ilaman a la prudencia. Ante las incompatibilidades entre la estructura administrativa y el objetivo del ordenamiento territorial, pueden preverse dos tipos de reformas: la creación de procedimientos de coordinación interministerial y la reforma regional. Como se mencionó, la conformación de comisiones intersecretariales ha sido recurrente en nuestra historia administrativa reciente en México. El funcionamiento de estos espacios de coordinación ha sido, en cambio, si no ineficaz, al menos desconocido, casi secreto. No sorprende, sin embargo, ese desempeño, pues si no en todos al menos en la mayoría de los casos esas comisiones 
han carecido de dos elementos centrales, de dos ingredientes que, por lo menos en el caso del exitoso periodo de los llamados "treinta (años) gloriosos" en Francia, fueron el motor del comité interministerial y de ordenamiento territorial (CIAT): por un lado, la participación directa del Primer Ministro, y por otro, la disposición de una suma importante de recursos a través de los Fondos de intervención para el ordenamiento territorial (FIAT) (Monod \& De Castelbajac, 1973). La más alta figura del gobierno y el factor financiero estaban presentes en este dispositivo: se contaba pues con la dirección política y con el recurso, dos elementos esenciales en todo juego gubernamental, y desde luego, en ese del ordenamiento territorial. No sin grandes cuestionamientos y errores fue en gran medida gracias a esos elementos, ausentes en el caso mexicano, que se puso en marcha una ambiciosa política de ordenamiento territorial en Francia.

En cuanto a la reforma regional, puede hacerse referencia a dos elementos. Es cierto que el ordenamiento territorial está basado en la idea de que existe una dimensión geográfica de los problemas económicos y sociales, y que la política de infraestructura $y$, en fin, las que inciden en el ordenamiento territorial deben estar adaptadas a las necesidades particulares del territorio funcional de esos problemas. Es en ese sentido que algunas de las iniciativas de reforma legislativa han intentado otorgar a la región un estatus jurídico específico y constituirla en ente receptor de intervenciones públicas ${ }^{30}$. Es posible que esa, desde muchos puntos de vista, fuera y siga siendo una reforma necesaria. Semejante transformación habría al

\footnotetext{
30 Son varias las iniciativas en este sentido, a manera de ejemplo, la presentada por el senador Carlos Rojas del grupo parlamentario del Partido Revolucionario Institucional en la legislatura 2000-2006 buscaba incorporar como objeto de planeación del desarrollo las figuras territoriales de la mesorregión y la región, crear las agencias regionales de desarrollo y en las que además se consideraba la figura de los Acuerdos de desarrollo mesorregionales, regionales y metropolitanos así como la correspondiente adjudicación de recursos financieros. Véase el dictamen de las Comisiones Unidad de Desarrollo Regional, Hacienda y Crédito Público, Desarrollo Social y Estudios Legislativos, del 29 de noviembre de 2005 .
}

menos contribuido en forma considerable a la ejecución del Programa Nacional de Desarrollo Urbano y Ordenación del Territorio 2001-2006 que, aunque estuvo vigente, fue a penas ejecutado de manera tímida y parcial.

Sin embargo, aunque deseable, habrá que esperar un tiempo considerable antes de que una semejante transformación vea el día. Por un lado porque al no ser políticamente ni electoralmente rentable, esta reforma no podrá filtrarse en una agenda política secuestrada por otros temas de coyuntura. Por otro, puesto que la reforma regional tiene un cierto rasgo de neutralidad política y ello puede ser un factor de consenso para sacarla adelante pero también para su congelamiento. En el supuesto de que se realizara esta reforma, será importante que aquello que introduzca en términos de estructuras de gestión de los territorios se construya sobre las estructuras jurídico-administrativas existentes, o bien si al disolverlas, no esté comprometiendo su viabilidad: la región y una estructura ad hoc a ella pueden ser útiles ahí donde los problemas de los municipios y los Estados no puedan ser resueltos a esas escalas o donde las medidas de ordenamiento territorial supongan intervenciones financieramente imposibles para estos niveles de gobierno. Pero es claro que no toda la acción pública local debe pasar por la escala regional. La región puede, de esta forma, ser algo accesorio pero no un sucedáneo de los Estados y municipios.

Más allá de los elementos intrínsecos a la Administración, el ordenamiento del territorio en tanto que busca redistribuir bienes y males sociales, enfrenta, en tanto que política, dificultades propias a toda política pública. Se trata de acciones que no son sino una condensación de intereses en tensión: por un lado, garantizar que cada individuo pueda establecerse en el lugar de su elección y entonces realizar su proyecto de vida, y por otro, buscar la utilización óptima, en términos de desarrollo económico, del territorio. Así, aunque sea presentada como una actividad de alto contenido técnico, el ordenamiento del territorio es sin duda una función de alto contenido político y entonces cargada de dificultades de las que no es posible ocuparse en este artículo. 


\section{Referencias bibliográficas}

ABOITES, L. La ilusión del poder nacional. Provisión de agua y alcantarillado en México, 1930-1990. En: LIRA, C. y RODRÍGUEZ, A. Ciudades Mexicanas del siglo XX. Siete estudios históricos. Ciudad de México: El Colegio de México, 2009, p. 181-216.

AGUILAR, L. El federalismo mexicano: funcionamiento y tareas pendientes. En Hernández, A., Hacia un nuevo federalismo? Ciudad de México: El Colegio de México y Fondo de Cultura Económica, 1996.

AZUELA, A. Algunos comentarios sobre la institucionalización de la planeación urbana en México. En: KAPLAN, M. Estudios de Derecho Económico. Ciudad de México: UNAM, 1986, p. 101-124.

AZUELA, A. La ciudad, la propiedad privada y el derecho. Ciudad de México: El Colegio de México, 1989.

AZUELA, A. La distribución de competencias en la regulación de los usos del suelo. En: INSTITUTO DE INVESTIGACIONES JURÍDICAS. PEMEX, Ambiente y energía. Los retos del futuro. Ciudad de México: PEMEX-UNAM, 1995, p. 13-55.

AZUELA, A. Distancias y disonancias del ordenamiento territorial en la legislación mexicana. En: DELGADILLO J. Política territorial en México. Hacia un modelo basado en el territorio. Ciudad de México: Plaza y Valdés, 2008, p. 509-535.

BALME, R.; GARRAUD, P.; HOFFMANMARTINOT, V. \& RITAINE, E. Les politiques territoriales en Europe de L'Ouest. Revue française de science politique, 1993, vol. 43, $\mathrm{N}^{\circ} 3$, p. 435-468.

BAZANT, J. Lineamientos para el ordenamiento territorial de las periferias urbanas de la Ciudad de México. Papeles de población, 2001, № 27, p. 222-139.

CABRERO, E. La nueva gestión municipal en México. Experiencias innovadoras en gobiernos locales. México. Centro de Investigación y Docencia EconómicasMiguel Ângel Porrúa, 1995.

CABRERO, E. Las políticas descentralizadoras en México, 1983-1993: logros y desencantos. México: Centro de Investigación y Docencia Económicas-Miguel Ángel Porrúa, 1998.

CARRERAS, G. y TAFUNELL, X. Historia económica de la España contemporánea. Barcelona: Crítica, 2004.

CONGRESO DE LA UNIÓN. Diario de Debates. Minuta Proyecto de Ley Orgánica de la Administración Pública Federal. Legislatura L - Año I - Período Ordinario. Ciudad de México: Cámara de Diputados del Congreso de la Unión, Diario No 54, 22 de diciembre de 1976a.

CONGRESO DE LA UNIÓN. Diario de Debates. Proyecto de Ley General de Asentamientos Humanos. Legislatura XLIX Año III - Período Extraordinario. Ciudad de México: Cámara de Diputados del Congreso de la Unión, Diario $N^{\circ}$ 3, 4 de mayo de 1976b.

CONGRESO DE LA UNIÓN. Diario de Debates (Exposición de Motivos del Presupuesto de Egresos de la Federación). Legislatura L - Año I - Período Ordinario. Ciudad de México: Cámara de Diputados del Congreso de la Unión, Diario $N^{\circ} 49,15$ de diciembre de 1976c.

CORTEZ, H. y DELGADILLO, J. Alcances del ordenamiento territorial en la planificación del desarrollo. Elementos conceptuales. En: DELGADILlO, J. Política territorial en México. Hacia un modelo basado en el territorio. Ciudad de México: Plaza y Valdés, 2008, p. 55-105.

DIARIO OFICIAL DE LA FEDERACIÓN. Decreto de creación de la Secretaría de Comunicaciones y Obras Públicas. Publicación periódica, 13 de mayo de 1891.

DIARIO OFICIAL DE LA FEDERACIÓN. Ley de Secretarías de Estados. Publicación periódica, 14 de abril de 1917. 
DIARIO OFICIAL DE LA FEDERACIÓN. Decreto por el cual se autoriza al Ejecutivo para ministrar el gobierno del Estado de San Luis Potosí la cantidad de cincuenta mil pesos con destino a la construcción de carreteras. Publicación periódica, 10 de febrero de 1927.

Diario Oficial de la Federación. Ley sobre planeación general de la república. Publicación periódica, 27 de enero de 1930.

Diario Oficial de la Federación. Reformas a la Ley sobre planeación de la república. Publicación periódica, 12 de julio de 1930.

DIARIO OFICIAL DE LA FEDERACIÓN. Ley de planificación y zonificación del Distrito Federal y Territorios de la Baja California. Publicación periódica, 17 de enero de 1933.

DIARIO OFICIAL DE LA FEDERACIÓN. Reglamento de la ley de planificación y zonificación. Publicación periódica, 22 de febrero de 1933.

DIARIO OFICIAL DE LA FEDERACIÓN. Reglamento para el servicio de colonización del Sistema nacional de riego $n^{\circ} 1$ "Presidente Calles". Publicación periódica, 7 de octubre de 1933.

DIARIO OFICIAL DE LA FEDERACIÓN. Ley de planificación y zonificación del Distrito Federal. Publicación periódica, 31 de agosto de 1936.

DIARIO OFICIAL DE LA FEDERACIÓN. Reglamento de la ley de planificación y zonificación del Distrito Federal. Publicación periódica, 31 de agosto de 1936.

DIARIO OFICIAL DE LA FEDERACIÓN. Decreto por el cual se demarcan las atribuciones que, en materia de planificación y zonificación, competen a la Comisión del ramo y a la Dirección General de Obras Públicas. Publicación periódica, 14 de octubre de 1941.

DIARIO OFICIAL DE LA FEDERACIÓN. Comité intersecretarial de la Habitación para los trabajadores a iniciativa de la Secretaría del Trabajo y Previsión Social. Publicación periódica, 19 de noviembre de 1941.
DIARIO OFICIAL DE LA FEDERACIÓN. Ley que exime del impuesto sobre actividades mercantiles e industriales, a las industrias nuevas en el Distrito Federal. Publicación periódica, 15 de diciembre de 1942.

DIARIO OFICIAL DE LA FEDERACIÓN. Autorización para la exención de impuestos otorgadas a empresas Hojalata y Lámina, S. A. Publicación periódica, 6 de abril de 1946.

DIARIO OFICIAL DE LA FEDERACIÓN. Creación del Comité Pro carreteras del valle de Mexicali. Publicación periódica, 11 de abril de 1947.

DIARIO OFICIAL DE LA FEDERACIÓN. Decreto que crea el Departamento de planeación y fomento de carreteras vecinales. Publicación periódica, 24 de junio de 1947.

DIARIO OFICIAL DE LA FEDERACIÓN. Comisión intersecretarial de la región indígena del valle del Yaqui. Publicación periódica, 16 de noviembre de 1951.

DIARIO OFICIAL DE LA FEDERACIÓN. Reforma al Reglamento de la Ley de planificación y zonificación del Distrito Federal. Publicación periódica, 28 de febrero de 1952.

DIARIO OFICIAL DE LA FEDERACIÓN. Comisión intersecretarial coordinadora del levantamiento de la carta geográfica de la república mexicana. Publicación periódica, 2 de enero de 1956.

DIARIO OFICIAL DE LA FEDERACIÓN. Ley de Secretarías de Estado. Publicación periódica, 24 de diciembre de 1958.

DIARIO OFICIAL DE LA FEDERACIÓN. Comisión intersecretarial para la formulación de planes nacionales para el desarrollo económico y social del país. Publicación periódica, 2 de marzo de 1962.

DIARIO OFICIAL DE LA FEDERACIÓN. Comisión nacional de zonas áridas. Publicación periódica, 5 de diciembre de 1970.

GARZA, G. Desconcentración, tecnología y localización industrial en México. Los 
parques y ciudades industriales, 1953-1988. Ciudad de México: El Colegio de México, 1992.

GARZA, G. La urbanización de México en el siglo XX. Ciudad de México: El Colegio de México, 2003.

HIERNAUX, D. Desarrollo territorial en México: un balance general. En: DELGADILLO, J. Política territorial en México. Hacia un modelo basado en el territorio. México: Plaza y Valdés, 2008, p. 107-134.

JIMÉNEZ, M. Constitución y Urbanismo. Ciudad de México: IIJ-UNAM, 2006.

MADIOT, Y. L'effacement de la politique d'aménagement du territoire. AJDA, 1989, $\mathrm{N}^{\circ}$ 12, p. 731-736.

MONOD, J. \& DE CASTELBAJAC, P. L'aménagement du territoire. Paris: PUF, 1973.

PARDO, M. C. La modernización administrativa en México. Ciudad de México: El Colegio de México, 1991.

RODRÍGUEZ, V. La descentralización en México. De la reforma municipal a Solidaridad y el nuevo federalismo. Ciudad de México: FCE, 1999.

RONDA, S. y UGALDE, V. Planeación urbana en la Ciudad de México en los cincuenta: controversias y debates en la Comisión de Planificación del Distrito Federal. Secuencia, 2008, № 70, p. 60-105.

RUIZ-MASSIEU, J. F. Derecho Urbanístico. Ciudad de México: IIJ-UNAM, 1981.

SÁNCHEZ, G. G. Planificación y urbanismo de la revolución mexicana. Ciudad de México: UAM-Azcapotzalco, 2002.

SÁNCHEZ, M. C. Rezagos de la modernidad. Memorias de una ciudad presente. Ciudad de México: UAM, 2005.

SECRETARÍA DE ASENTAMIENTOS HUMANOS Y OBRAS PÚBLICAS. Desarrollo Urbanos Nacional. Asistencia técnica a estados y municipios. Ciudad de México: SAHOP, s/f.

TORTORELLA, G. El desarrollo de la España contemporánea. Historia económica de los siglos XIX y XX. Madrid: Alianza, 1995.

WARD, P. México: una megaciudad: producción y reproducción de un medio ambiente urbano. Ciudad de México: Alianza, 1991.

WILK, D. La planeación del uso del suelo y medio ambiente en la Ciudad de México. En: GARZA, G. Una década de planificación urbano-regional en México, 1978-1988. Ciudad de México: El Colegio de México, 1989, p. 327-345. 